体力科学 (1995) $44,287 \sim 296$

\title{
METABOLIC FEATURES BY TYPE OF OBESITY, BASED ON BODY MASS INDEX AND WAIST TO HIP CIRCUMFERENCE RATIO IN JAPANESE WOMEN
}

\author{
ShUichi KomiYa* and TaKashi MASUdA **
}

\begin{abstract}
In 176 Japanese women aged $20 \sim 79$, participating in a health assessment programme, we studied the associations between several metabolic features and the type of obesity based on body mass index and waist to hip circumference ratio. We propose the existence of three types of obesity based on BMI and WHR: Type-I, obese women who have a high BMI and a low WHR. Type-II, obese women who have a low BMI and a high WHR, and Type-III, obese women who have both a high BMI and a high WHR. Age was categorized into three levels for all analyses ( $\leqq 49,50-59$, and $\geqq 60 \mathrm{yr}$ ). There was no significant association of WHR with any metabolic variable after adjustment for the effects of the BMI in any group. The results of the present study show that the amount of body fat is in itself more important than the WHR. Where $\mathrm{p}$ values were significant, levels of metabolic risk factors for disease increased across the tertiles composed from a combination of the BMI and WHR, except for HDL-ch and HDL-ch/T-ch, where levels fell. Although the means of these metabolic parameters in each type of obesity were all within the normal range, significant differences were observed between the group with Type-III obesity and the nonobese group for these parameters.

In conclusion, the most "dangerous" subgroup of obesity appeared to be Type-III obesity in which high levels of BMI and WHR coexist.
\end{abstract}

(Jpn. J. Phys. Fitness Med. 1995, $44: 287 \sim 296)$

key words : Body mass index, Waist-to-hip ratio, Type of obesity, Lipid and lipoprotein, Blood pressure, Dangerous subgroup of obesity

\section{I . Introduction}

Obesity has been generally defined as excessive storage of energy in the form of fat. Excess body weight, or more specifically excess body fat, influences the health risk profile and increases mortality and morbidity ${ }^{14,34)}$. Obesity is, however, a heterogeneous condition in terms of the topographical distribution of fat in each subject. The topography of body fat in humans has attracted the attention of obesity scientists and clinicians because of the apparent metabolic complications associated with excessive abdominal fat.

Vague $^{40.41)}$ was the first to point out that "android" or centralised obesity was more closely associated with diabetes, gout, and atherosclerosis than the more peripheral fat distribution associated with "gynaecoid" obesity. Recently, experimental and clinical observations have suggested that intra-abdominal visceral fat, particularly in the fat depots draining into the hepatic portal circulation, correlate best with of metabolic complications related to body fat distribu$\operatorname{tion}^{4.5 .9,20)}$. At this time, abdominal visceral fat is best assessed with computed tomography (CT). The distinction between "portal" and "nonportal" fat tissues is not, however, easily made with this technique.

Whereas anthropometry may be used to assess the relative distribution of fat in large numbers of
*九州大学健康科学センター 巴816 春日市春日公園6-1

**中村学園大学 E814-01 福岡市城南区別府5-7-1
Institute of Health Science, Kyushu University, Kasuga 816, Japan

Nakamura Gakuen University, Fukuoka 814-01, Japan 
patients, this is obviously not feasible with CT. The most popular anthropometric variable for describing body fat distribution is the ratio of waist-to-hip circumference (WHR). The WHR is positively correlated with the amount of visceral fat $^{26.30)}$, which is in turn associated with hyperinsulinemia, insulin resistance, and high free fatty acid levels, and thereby with impairment of glucose tolerance $^{7,11,27,29.31)}$, hypertension ${ }^{28,30)}$, and high triglyceride (TG) and low HDL-cholesterol (HDL-ch) levels $5,8,9,36$ )

According to various studies, the body mass index (BMI) appears to be a reasonably good index of adiposity in adults ${ }^{2.12 .18)}$. Moreover, several studies have demonstrated that BMI and age are, in addition to gender, the most important vari-

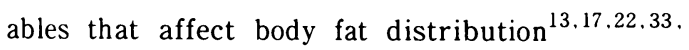
38.39 ). Previous studies have also suggested that the prevalence of hypertension, hyperlipidemia and hyperuricemia increase with the $\mathrm{BMI}^{15,25,37)}$. However, the BMI does not take into account frame size or variation in the body fat pattern, both of which may be related to the health risk profile.

Abdominal obesity and peripheral obesity are the two representative categories into which obesity is currently classified. The frequencies of metabolic complications, including glucose intolerance and hyperlipidemia, have been shown to be quite different between these two types of obesity. We propose the existence of three types of obesity: Type-I obesity, characterized by a pronounced accumulation of subcutaneous fat, Type-II obesity, characterized by fat accumulation mainly in the abdominal cavity, and Type-III obesity, characterized by a pronounced accumulation of both abdominal and subcutaneous fat.

In this study the association of these three types of obesity with metabolic features was examined in a group of Japanese women.

\section{Materials and methods}

\section{A. Subjects}

The subjects of this study were 176 female volunteers referred to the Institute of Health Science at Kyushu University for health assessment.

Table 1. Means and standard deviations for descriptive variables in 176 women.

\begin{tabular}{|c|c|c|c|c|c|}
\hline & $\begin{array}{c}\leq 49 y r \\
n=68\end{array}$ & $\begin{array}{c}50-59 y r \\
n=59\end{array}$ & $\begin{array}{c}60 y r \leq \\
\mathrm{n}=49\end{array}$ & $\mathbf{p}$ & $\begin{array}{l}\text { Total } \\
N=176\end{array}$ \\
\hline Age, yr & $41.1 \pm 7.4$ & $54.1 \pm 3.0$ & $64.5 \pm 4.0$ & 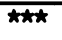 & $52.0 \pm 10.9$ \\
\hline Height, ca & $155.0 \pm 4.3$ & $152.0 \pm 6.1$ & $151.7 \pm 5.1$ & 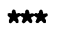 & $153.1 \pm 5.4$ \\
\hline Weight, kg & $59.97 \pm 8.92$ & $57.80 \pm 7.46$ & $53.83 \pm 7.19$ & 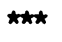 & $57.53 \pm 8.32$ \\
\hline Body Mass Index, $\mathrm{kg} / \mathrm{m}^{2}$ & $24.92 \pm 3.71$ & $25.08 \pm 3.35$ & $23.37 \pm 2.70$ & $\star$ & $24.53 \pm 3.8$ \\
\hline Abdominal circunference, $\mathrm{cm}$ & $80.9 \pm 9.8$ & $82.5 \pm 9.9$ & $80.7 \pm 8.8$ & n. 8 & $81.4 \pm 9.6$ \\
\hline Hip circunference, cn & $91.0 \pm 5.5$ & $89.3 \pm 4.1$ & $87.6 \pm 4.2$ & 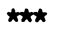 & $89.5 \pm 4.9$ \\
\hline Waist-to-Hip Ratio & $0.886 \pm 0.071$ & $0.921 \pm 0.080$ & $0.919 \pm 0.071$ & $\star$ & $0.907 \pm 0.076$ \\
\hline Triceps skinfold, an & $19.1 \pm 4.9$ & $19.2 \pm 5.7$ & $18.1 \pm 4.5$ & n. 8 & $18.8 \pm 5.1$ \\
\hline Sub-scapular skinfold, an & $24.5 \pm 8.4$ & $24.3 \pm 8.5$ & $20.6 \pm 6.5$ & $\star$ & $23.4 \pm 8.1$ \\
\hline Tota1-cholesterol, ng/de & $203 \pm 34.2$ & $220 \pm 34.0$ & $224 \pm 27.6$ & $\star \star$ & $215 \pm 33.5$ \\
\hline 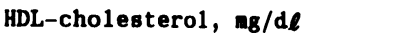 & $59 \pm 14.9$ & $58 \pm 14.9$ & $61 \pm 14.2$ & n. $\mathbf{B}$ & $59 \pm 14.7$ \\
\hline $\mathrm{HDL} / \mathrm{T}-\mathrm{ch}$ & $0.30 \pm 0.09$ & $0.27 \pm 0.07$ & $0.28 \pm 0.07$ & n.s & $0.28 \pm 0.08$ \\
\hline LDL-cholesterol, $n g / d \ell$ & $127 \pm 34.5$ & $142 \pm 31.7$ & $142 \pm 27.4$ & $\star \star$ & $136 \pm 32.4$ \\
\hline Triglyceride, mg/dl & $86 \pm 40.8$ & $98 \pm 46.1$ & $100 \pm 61.8$ & n. $\mathbf{8}$ & $94 \pm 49.3$ \\
\hline Glucose, mg/de & $93 \pm 13.6$ & $91 \pm 9.2$ & $92 \pm 9.8$ & n. 8 & $92 \pm 11.2$ \\
\hline Systolic blood pressure, mmHg & $116 \pm 15.0$ & $123 \pm 16.3$ & $129 \pm 15.6$ & 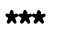 & $121 \pm 16.4$ \\
\hline Diastolic blood pressure, maHg & $67 \pm 9.8$ & $68 \pm 9.9$ & $72 \pm 9.8$ & $\star$ & $69 \pm 10.0$ \\
\hline
\end{tabular}

$\mathrm{P}$ values were calculated using one-way analysis of variance, n. s. ; non-significant, ${ }^{*} ; \mathrm{p}<0.05$, ${ }^{* *} ; \mathrm{p}<0.01,{ }^{* * *} ; \mathrm{p}<0.001$. 
The volunteers ranged in age from 20 to $79 \mathrm{yrs}$, and had no known diabetes mellitus, other endocrine disorders or cardiovascular disease. The purpose of the investigation was fully explained to each participant, and all gave written informed consent before commeneing the study. This population included subjects with a wide range of BMI (from 15.85 to $32.56 \mathrm{~kg} / \mathrm{m}^{2}$ ) and WHR (from 0.685 to 1.074$)$. Their physical characteristics are summarized in Table 1.

\section{B. Anthropometry}

The waist and hip circumferences, triceps and sub-scapular skinfold thicknesses, body weight, and height were picked out as anthropometric measures. Body weight and height were measured in subjects wearing light clothing without shoes. The BMI was calculated from the formula weight/ height $^{2}\left(\mathrm{~kg} / \mathrm{m}^{2}\right)$. Waist circumference $(\mathrm{cm})$ was measured at the level of the umbilicus, and hip circumference at the position of its largest, while the subject breathed normally. An inelastic tape was used for circumference measurements, and the skin was not compressed. In an attempt to determine the predictive power of abdominal adipose tissue distribution the WHR was calculated. A Harpenden calliper was used for skinfold thickness measurements. The subject stood erect during all measurements. All anthropometric measurements were performed by a single observer.

\section{Metabolic parameters}

Blood samples were obtained from each subject after an overnight fast. Serum total cholesterol $(\mathrm{T}-\mathrm{ch})$ and triglyceride (TG) levels were determined by enzymatic methods. Serum HDL-ch was measured by a precipitation method. Plasma glucose (GL) was measured by the glucose oxidase method. All biochemical analyses were performed at Creative Research Community, Inc., Fukuoka. The very-low-density lipoprotein cholesterol (VLDL-ch) and low-density lipoprotein choles- terol (LDL-ch) values were calculated using the equations of Friedewald et al. ${ }^{10)}$, where VLDL-ch $=\mathrm{TG} / 5$ and $\mathrm{LDL}-\mathrm{ch}=\mathrm{T}-\mathrm{ch}-(\mathrm{HDL}-\mathrm{ch}+\mathrm{VLDL}-$ ch). The ratio of HDL-ch to $\mathrm{T}-\mathrm{ch}$, which has been proposed to be the best predictor of coronary artery disease ${ }^{6)}$, was used in this study. Systolic blood pressure (SBP) and diastolic blood pressure (DBP) were measured three times in the right arm over a period of $10 \mathrm{~min}$ with the subject seated, using an automatic sphygmomanometer (BP-203 NP, NIPPON COLIN Co., Ltd., Tokyo). The mean value of the three blood pressure readings was used in subsequent analyses.

\section{Statistical analysis}

Age was categorized into three levels for all analyses $(20 \sim 49,50 \sim 59$, and $60 \sim 79 \mathrm{yr})$. The cut-off points for each metabolic variable were determined based on the following abnor$\mathrm{mal}$ ranges $-\geqq 220 \mathrm{mg} / \mathrm{d} \ell(\mathrm{T}-\mathrm{ch}), \leqq 40 \mathrm{mg} / \mathrm{d} \ell$ (HDL-ch), $\leqq 0.18$ (HDL-ch/T-ch), $\geqq 150 \mathrm{mg} / \mathrm{d} \ell$ (LDL-ch), $\geqq 150 \mathrm{mg} / \mathrm{d} \ell$ (TG), $\geqq 110 \mathrm{mg} / \mathrm{d} \ell$ (GL), $\geqq 140 \mathrm{mmHg}(\mathrm{SBP})$ and $\geqq 85 \mathrm{mmHg}$ (DBP). Tertiles for BMI and WHR distribution were determined from the mean value in sample women with metabolic parameter values higher or lower than the cut-off points for each metabolic variable. Thereafter, the obese women were divided into three groups according to these BMI and WHR tertiles (Table 5, 6, and 7). Results are presented as mean \pm standard deviation. Data were analysed using correlation coefficients and partial correlation coefficients. Adjustments for BMI or WHR were made by partial correlation. Differences with $\mathrm{p}$ values below 0.05 were regarded as statistically significant.

\section{Results}

The relationships between the BMI and WHR and the metabolic variables are shown in Table 2 . The $\mathrm{T}$-ch concentration was not significantly correlated with BMI or WHR. Furthermore, with 
Table 2. Significant Pearson's correlation coefficients between metabolic features and BMI, and WHR.

\begin{tabular}{|c|c|c|c|c|c|c|}
\hline & \multicolumn{3}{|c|}{ BMI } & \multicolumn{3}{|c|}{ WHR } \\
\hline & $\$ 49 \mathrm{yr}$ & $50-59 y r$ & $60 y r s$ & $\$ 49 \mathrm{yr}$ & $50-59 y r$ & $60 y r s$ \\
\hline T-ch. & - & - & - & - & - & - \\
\hline HDL-ch. & $-0.520 k \star \star$ & $-0.383 * \star$ & $-0.419 \star \star$ & $-0.445 * k \star$ & $-0.428 * k *$ & $-0.296 *$ \\
\hline HDL-ch./T-ch. & 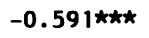 & $-0.264 \star$ & $-0.380 k t$ & $-0.495 * \hbar \star$ & $-0.345 \star \star x$ & $-0.325 *$ \\
\hline LDL-ch. & $0.332 \star \star$ & - & - & - & - & - \\
\hline TG & $0.279 \star$ & - & 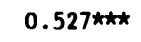 & $0.291 *$ & $0.280 *$ & - \\
\hline GL & $0.393 k x *$ & - & - & - & $0.295 \star$ & - \\
\hline SBP & - & $0.437 * k \star$ & - & $0.265^{\star}$ & $0.465 * k \star$ & - \\
\hline DBP & - & $0.422 * k \star$ & - & - & $0.496 * k \star$ & - \\
\hline
\end{tabular}

the exception of BMI in the group aged 49 and below, the LDL-ch concentration was not associated with BMI or WHR. The HDL-ch and $\mathrm{HDL}-\mathrm{ch} / \mathrm{T}$-ch concentrations were significantly and negatively correlated with BMI and WHR, whereas TG, GL, SBP and DBP were positively correlated with these variables.

Figure 1 shows the relationship between the BMI and WHR. The correlation coefficient between the BMI and WHR was significant $(p<$ 0.001 ) in each group. Because the BMI and WHR were significantly correlated, partial correlation analyses were used to determine how much the BMI and WHR correlate independently with the metabolic variables.

Table 3 shows the significant partial correlation of the BMI with each metabolic variable with the WHR partialed out, and for the WHR and each metabolic variable with the BMI partialed out. The BMI remained with WHR partialed out significantly related to HDL-ch, HDL-ch/T-ch, LDL-ch and GL in the group aged 49 and below. There was no significant association of WHR with any metabolic variable with the effects of the BMI partialed out in any group.

To investigate the pathogenic relationships of the metabolic factors to the type of obesity, we calculated the levels of BMI and WHR in a sample of patients with metabolic variable values higher

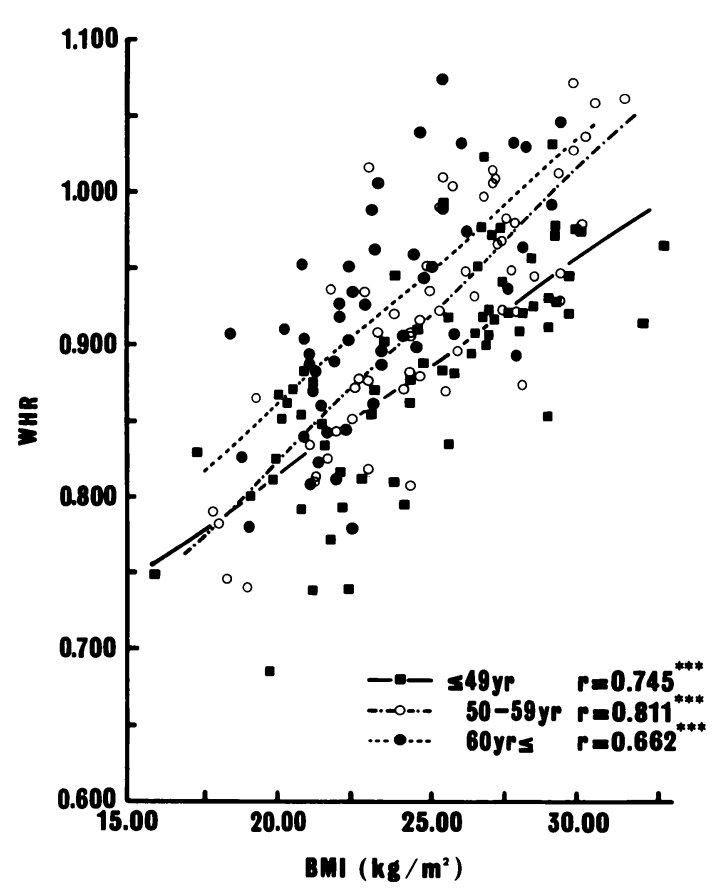

Fig. 1. Scatterplots showing correlation between the body mass index (BMI) and waist-to-hip circumference ratio (WHR) in female subjects.

or lower than the cut-off point. The results are presented in Table 4 . We defined the cut-off points for the BMI tertiles in each metabolic variable group as $27.28,26.92$, and $26.23 \mathrm{~kg} / \mathrm{m}^{2}$, respectively. For WHR, cut-off points were $0.929,0.975$, and 0.950 , respectively.

The means for the various metabolic variables 
Table 3. Significant relationship of the WHR and BMI to metabolic features after controlling for each WHR and BMI in female subjects.

\begin{tabular}{|c|c|c|c|c|c|c|}
\hline & \multicolumn{6}{|c|}{ Controlling for: } \\
\hline & WHR & BMI & WHR & BMI & UHR & BMI \\
\hline & \multicolumn{2}{|c|}{$\$ 49 \mathrm{yr}$} & \multicolumn{2}{|c|}{$50-59 y r$} & \multicolumn{2}{|c|}{$60 y r s$} \\
\hline \multirow[t]{2}{*}{ Dependent } & variable; & & & & & \\
\hline & BMI & WHR & BMI & WHR & BMI & WHR \\
\hline HDL-ch. & $-0.316 \star \star$ & - & - & - & $-0.312 \star$ & - \\
\hline HDL-ch. /T-ch. & 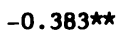 & - & - & - & - & - \\
\hline LDL-ch. & $0.264 \star$ & - & $x$ & $x$ & $x$ & $x$ \\
\hline TG & - & - & - & - & $0.497 \star \star \star$ & - \\
\hline GL & $0.383 * \star$ & - & - & - & $x$ & $x$ \\
\hline SBP & - & - & - & - & $x$ & $x$ \\
\hline DBP & $x$ & $x$ & - & $0.290 \star$ & $x$ & $x$ \\
\hline
\end{tabular}

Table 4. Means and standard deviations of BMI and WHR on the cut-off points for each metabolic variabie.

\begin{tabular}{|c|c|c|c|c|c|c|c|c|c|}
\hline & \multirow[b]{2}{*}{$\mathrm{n}$} & \multicolumn{2}{|c|}{$549 \mathrm{yr}$} & \multicolumn{3}{|c|}{$50-59 \mathrm{yr}$} & \multirow[b]{2}{*}{$\mathrm{n}$} & \multicolumn{2}{|c|}{$60 y r s$} \\
\hline & & BMI & WHR & $\mathrm{n}$ & BMI & WHR & & BMI & WHR \\
\hline $\mathrm{HDL}-\mathrm{ch}$ & 4 & $28.74 \pm 1.10$ & $0.952 \pm 0.029$ & 5 & $26.24 \pm 1.04$ & $0.988 \pm 0.025$ & 2 & $26.30 \pm 2.24$ & $0.919 \pm 0.036$ \\
\hline $\mathrm{HDL}-\mathrm{ch} . / \mathrm{T}-\mathrm{ch}$. & 3 & $28.57 \pm 1.07$ & $0.976 \pm 0.003$ & 6 & $27.19 \pm 2.17$ & $0.988 \pm 0.043$ & 3 & $24.52 \pm 3.38$ & $0.942 \pm 0.084$ \\
\hline $\mathrm{LDL}-\mathrm{ch}$ & 19 & $26.46 \pm 2.90$ & $0.912 \pm 0.072$ & & & & & & \\
\hline TG & 6 & $25.77 \pm 3.19$ & $0.940 \pm 0.045$ & 9 & $26.52 \pm 2.49$ & $0.959 \pm 0.064$ & 7 & $26.95 \pm 2.18$ & $0.962 \pm 0.071$ \\
\hline GL & 6 & $29.10 \pm 2.04$ & $0.913 \pm 0.043$ & 4 & $25.96 \pm 1.81$ & $0.955 \pm 0.046$ & & & \\
\hline SBP & 6 & $27.96 \pm 4.31$ & $0.953 \pm 0.069$ & 10 & $27.68 \pm 2.18$ & $0.984 \pm 0.050$ & & & \\
\hline DBP & & & & 2 & $27.73 \pm 1.06$ & $0.980 \pm 0.049$ & & & \\
\hline Total & 44 & $27.28 \pm 2.99$ & $0.929 \pm 0.061$ & 36 & $26.92 \pm 2.04$ & $0.975 \pm 0.049$ & 12 & $26.23 \pm 2.50$ & $0.950 \pm 0.067$ \\
\hline
\end{tabular}

cut-off points : T-ch. $\geqq 220 \mathrm{mg} / \mathrm{d} \ell, \mathrm{HDL}-\mathrm{ch} . \leqq 40 \mathrm{mg} / \mathrm{d} \ell, \mathrm{HDL}-\mathrm{ch} . / \mathrm{T}-\mathrm{ch} . \leqq 0.18, \mathrm{LDL}-\mathrm{ch} . \geqq 150 \mathrm{mg} / \mathrm{d} \ell$. $\mathrm{TG} \geqq 150 \mathrm{mg} / \mathrm{d} \ell, \mathrm{GL} \geqq 110 \mathrm{mg} / \mathrm{d} \ell, \mathrm{SBP} \geqq 140 \mathrm{mmHg}, \mathrm{DBP} \geqq 85 \mathrm{mmHg}$.

were calculated across the tertiles of a combination of the BMI and WHR for the three age groups separately, as shown in Tables 5,6 , and 7 . Levels of all risk factors varied significantly across the tertiles in the group aged 60 and over, and all factors except LDL-ch and SBP varied significantly

Table 5. Means of metabolic features by the type of obesity in female subjects aged 49 and below.

\begin{tabular}{|c|c|c|c|c|c|c|c|c|c|c|c|c|c|}
\hline \multirow[b]{3}{*}{ BMI } & \multirow{2}{*}{$\begin{array}{c}\text { Norma } 1 \\
n=42\end{array}$} & \multirow{2}{*}{\multicolumn{3}{|c|}{$\begin{array}{c}\text { Type- } 1 \\
\mathrm{n}=9 \\
\end{array}$}} & \multirow{3}{*}{$\frac{t}{\star \star \star}$} & \multicolumn{4}{|c|}{ Type-1 } & \multirow{2}{*}{\multicolumn{2}{|c|}{$\begin{array}{r}\text { Type-1 } \\
\mathrm{n}=11\end{array}$}} & \multirow{3}{*}{$\frac{t}{\star \star \star}$} & \multirow{3}{*}{$\frac{p}{\star \star \star}$} \\
\hline & & & & & & \multirow{3}{*}{\multicolumn{2}{|c|}{$\begin{array}{r}\mathrm{n}= \\
25.98 \pm \\
0.977 \pm\end{array}$}} & $=6$ & \multirow{2}{*}{$\frac{t}{\star \star}$} & & & & \\
\hline & $22.76 \pm 2.80$ & 29.02 & \pm & 1.32 & & & & 1.23 & & $29.26 \pm$ & 1.42 & & \\
\hline WHR & $0.847 \pm 0.057$ & 0.912 & \pm & 0.023 & $3 * \star$ & & & 0.029 & $9 \star \star \star$ & $0.968 \pm$ & 0.027 & $7 \star \star \star \star$ & $\star \star \star$ \\
\hline HDL-ch. & $64 \pm 14.4$ & 52 & & 12.6 & * & 56 & & 8.7 & n.s & $48 \pm$ & 13.8 & $\star \star \star$ & $\star \star$ \\
\hline HDL-ch. /T-ch. & $0.32 \pm 0.09$ & 0.27 & \pm & 0.06 & n.s. & 0.27 & \pm & 0.06 & n.s & $0.24 \pm$ & 0.06 & $\star \star$ & $\star \star$ \\
\hline LDL-ch. & $123 \pm 35.7$ & 128 & \pm & 39.9 & n. 8 & 142 & & 29.0 & n.s & $133 \pm$ & 28.2 & $\mathbf{n . 8}$ & n. 8 \\
\hline TG & $79 \pm 35.9$ & 93 & \pm & 37.7 & n.s & 72 & & 48.0 & n.s & $115 \pm$ & 47.6 & $\star \star$ & $\star$ \\
\hline GL & $90 \pm 12.7$ & 96 & \pm & 14.8 & n.s & 87 & & 12.2 & n.s & $102 \pm$ & 12.5 & $\star \star \star$ & $\star$ \\
\hline SBP & $113 \pm 13.0$ & 112 & \pm & 13.8 & n.s & 119 & \pm & 7.1 & n.s & $126 \pm$ & 22.0 & n.s & n. 8 \\
\hline
\end{tabular}

Normal ; BMI < 27.28: WHR < 0.929, Type- I ; BMI $\geqq 27.28:$ WHR < 0.929, Type- II ; BMI < 27.28 : WHR $\geqq 0.929$. Type- III ; BMI $\geqq 27.28$ : WHR $\geqq 0.929, T$ values were calculated between normal and each type of obesity using unpaired Student's t test. $\mathrm{P}$ values were calculated using one-way analysis of variance, n. s ; non-significant, ${ }^{*} ; p<0.05,{ }^{* *} ; p<0.01$, $* * * \mathrm{p} ;<0.001$. 
Table 6. Means of metabolic features by the type of obesity in female subjects aged from 50 to 59 years.

\begin{tabular}{|c|c|c|c|c|c|c|c|c|c|c|c|c|c|c|}
\hline \multirow[b]{3}{*}{ BMI } & \multirow{2}{*}{\multicolumn{2}{|c|}{$\begin{array}{c}\text { Norma } 1 \\
n=33\end{array}$}} & \multirow{2}{*}{\multicolumn{3}{|c|}{$\begin{array}{c}\text { Type-1 } \\
n=9\end{array}$}} & \multirow{3}{*}{$\frac{t}{\hbar \star \hbar}$} & \multicolumn{4}{|c|}{ Type-I } & \multirow{2}{*}{\multicolumn{2}{|c|}{$\begin{array}{r}\text { Type-I } \\
n=12\end{array}$}} & \multirow{3}{*}{$\frac{t}{\star \star \star \star}$} & \multirow{3}{*}{$\frac{p}{\hbar k \star}$} \\
\hline & & & & & & & & $\mathbf{n}=5$ & & $t$ & & & & \\
\hline & $22.84 \pm$ & 2.39 & 28.10 & \pm & 0.85 & & 25.15 & \pm & 1.33 & $\star$ & $28.95 \pm$ & 1.59 & & \\
\hline WHR & $0.869 \pm$ & 0.057 & 0.936 & \pm & 0.029 & $9 \star \star$ & 1.003 & \pm & 0.010 & $0 * \star * \hbar$ & $1.020 \pm$ & 0.032 & $2 \star \star \star$ & $\star \star \star \star$ \\
\hline HDL-ch. & $63 \pm$ & 14.7 & 55 & & 9.3 & n.s & 47 & & 27.9 & n.8 & $47 \pm$ & 11.7 & $\star \star$ & $\star \star$ \\
\hline HDL-ch. /T-ch. & $0.28 \pm$ & 0.07 & 0.28 & \pm & 0.07 & n.s & 0.26 & \pm & 0.10 & $\mathbf{n . s}$ & $0.22 \pm$ & 0.06 & $\star$ & n. $\mathbf{8}$ \\
\hline TG & $87 \pm$ & 44.0 & 86 & & 36.0 & n.s & 116 & & 42.9 & n. 8 & $128 \pm$ & 48.1 & $\star$ & $\star$ \\
\hline GL & $88 \pm$ & 9.5 & 93 & \pm & 9.4 & n.s & 93 & \pm & 6.9 & n.s & $95 \pm$ & 7.8 & $\star$ & n. $\mathbf{s}$ \\
\hline SBP & $119 \pm$ & 16.1 & 119 & & 13.7 & n.s & 127 & & 14.9 & n. 8 & $132 \pm$ & 16.4 & $\star$ & n. 8 \\
\hline DBP & $66 \pm$ & 10.1 & 67 & & 8.8 & n. 8 & 74 & \pm & 9.9 & n. 8 & $74 \pm$ & 8.1 & * & n.s \\
\hline
\end{tabular}

Normal ; BMI $<26.92$ : WHR $<0.975$, Type- I ; BMI $\geqq 26.92:$ WHR $<0.975$, Type- II ; BMI $<$ 26.92 : WHR $\leqq 0.975$, Type- III ; BMI $\geqq 26.92$ : WHR $\geqq 0.975$, T values were calculated between normal and each type of obesity using unpaired Student's $t$ test, $P$ values were calculated using one-way analysis of variance, n. s; non-significant, ${ }^{*} ; \mathrm{p}<0.05,{ }^{* *} ; \mathrm{p}<0.01$, $* * * ; p<0.001$.

Table. 7. Means of metabolic features by the type of obesity in female subjects aged 60 and over.

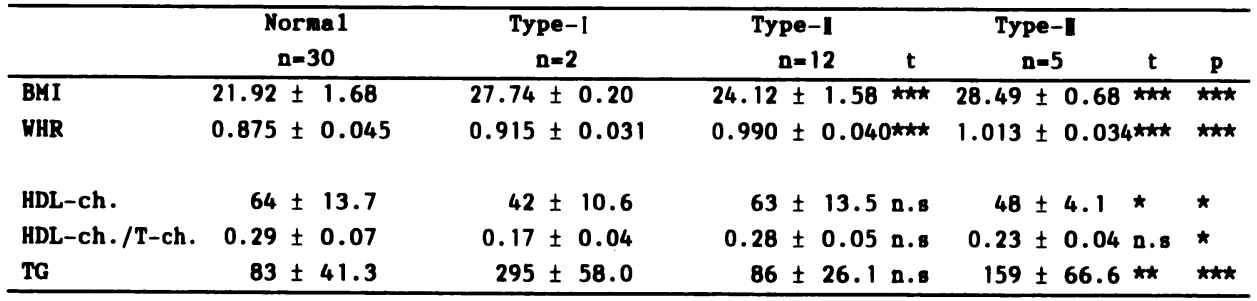

Normal ; BMI $<26.23$ : WHR $<0.950$, Type- I ; BMI $\geqq 26.23:$ WHR $<0.950$, Type- II ; BMI < 26.23 : WHR $\geqq 0.950$, Type- III ; BMI $\geqq 26.23$ : WHR $\geqq 0.950$, $\mathrm{T}$ values were calculated between normal and each type of obesity using unpaired Student's $t$ test, $P$ values were calculated using one-way analysis of variance, n. s ; non-significant, ${ }^{*} ; \mathrm{p}<0.05,{ }^{* *} ; \mathrm{p}<0.01$, $* * * ; p<0.001$

across the tertiles in the group aged 49 and below. The BMI and WHR tertiles were related to fewer variables in the group aged between 50 and $59 \mathrm{yr}$, with only $\mathrm{HDL}-\mathrm{ch}$ and TG varying significantly across the tertiles. Where $\mathrm{p}$ values were significant, levels of risk factors increased across the tertiles, except for HDL-ch and HDL-ch/T-ch, where levels fell. However, the obese women with high levels of BMI and low levels of WHR (Type-I) did not differ significantly from the nonobese groups, except in the group aged 60 and over $(n=2)$. Moreover, no significant differences were seen between the obese women who had a low levels of BMI and high levels of WHR (Type-II) and the nonobese group in any age group. Although the mean values, of these metabolic parameters in each type of obesity were all within the normal range, significant differences were observed between obese women with high levels of BMI and WHR (Type-III) and the nonobese group in these parameters. Consequently, the most "dangerous" subgroup of obesity appeared to be Type-III obesity, the levels of both BMI and WHR were high.

\section{$N$. Discussion and conclusion}

In the developed countries, overeating and decreased muscular exercise are responsible for the increasing incidence of various types of obesity. Previous studies have generally demonstrated 
only small degrees of correlation between increased body fat and either serum $\mathrm{T}$-ch or TG levels ${ }^{16,24)}$. It has been established that obesity is an independent risk factor for cardiovascular disease $^{14)}$. Obesity is, however, associated with several cardiovascular risk factors; elevated $\mathrm{T}-\mathrm{ch}^{1)}$ and TG levels ${ }^{1.3)}$, reduced HDL-ch levels ${ }^{1)}$, hypertension ${ }^{35)}$, and noninsulin-dependent diabetes ${ }^{23)}$. Although obesity itself may not be a major determinant of blood lipid levels, adipose tissue distribution appears to contribute independently to the level of TG. Scientific assessment in recent years has revealed that morbidity and mortality in obese subjects are closely related to regional body fat distribution.

Obesity has been generally defined as an excessive storage of energy reserves in the form of fat. Furthermore, obesity is a heterogeneous condition in terms of the topographical distribution of adipose tissue in each subject. The risks of obesity therefore depend on the distribution of fat as well as the total amount of fat. Perhaps an index of fat distribution, such as WHR, should be included in the definition of medically significant obesity in combination with the BMI.

The main criticism which has been given on the BMI as a measure of obesity is that it is less closely related to body fat than, for example, skinfold thickness ${ }^{42)}$. Skinfold thickness is a convenient method for measuring obesity, and skinfolds are well correlated with estimates of body fat based on density. However, we have found that there is considerable variation between the values obtained by particular methods of estimating body fat, such as skinfold thickness, density, and water or potassium content ${ }^{21)}$. On the other hand, the practical advantages of BMI are obvious; both weight and height can be measured easily and accurately with simple equipment. According to various studies, BMI appears to be a reasonably good index of adiposity in adults ${ }^{2,12,18)}$. Previous studies have suggested that the prevalence of hypertension, hyperlipidemia and hyperuricemia increases with the $\mathrm{BMI}^{15,25,37)}$. Therefore, it is now common to use the BMI as a reasonable index of obesity within a population because it is easy to measure and because it has shown reasonably good correlation with the more direct measurements of obesity. However, the BMI does not take into account frame size or variation in the body fat pattern, both of which may be related to the health risk profile.

In 1947 Vague $^{40)}$ first reported the relationship between regional fat distribution and complications in obese subjects. The new techniques of CT and magnetic resonance imaging (MRI) now allow the direct non-invasive measurement of intraabdominal fat depots ${ }^{32)}$. These techniques, however, are expensive and can only be used within hospitals and research centers, they cannot be used for routine community measurements. Kissebah et al. ${ }^{19)}$ simplified the indicators of adipose tissue distribution by using WHR, and defined those with a high WHR as being obese in the upper body segment. Subsequently, the most popular measurement in recent years has been the WHR.

We propose the existence of three types of obesity based on BMI and WHR: Type-I, obese women who have a high BMI and a low WHR, Type-II, obese women who have a low BMI and a high WHR, and Type-III, obese women in whom both BMI and WHR are high. In the present study the association of these three types of obesity with metabolic features are examined in this group of Japanese women. Because of the possible effects of sex hormones on the results, similar analyses were performed within age categories, using aged 49 and below, aged between 50 and 59 yr, and aged 60 and over as cutoff points. The HDL-ch and HDL-ch/T-ch were significantly and inversely correlated with BMI and WHR, whereas TG, GL, SBP and DBP were positively correlated 
with these variables. However, there was no sig. nificant association of WHR with any metabolic variable with the effects of the BMI partialed out in any group. The results of the present study show that the amount of body fat is in itself more important than the WHR. However, it is also evident that the WHR enhances the concomitant effects of obesity on metabolism. To investigate the pathogenic relationship of metabolic factors to the type of obesity, we calculated the BMI and WHR in sample women with metabolic parameter values higher or lower than the cut-off point for each metabolic variable. The mean values of the various metabolic variables across tertiles of a combination of the BMI and WHR were calculated for the three age groups separately. Where $p$ values were significant, levels of these metabolic risk factors increased across tertiles, except for HDL-ch and HDL-ch/T-ch whose levels fell. Although the means of these metabolic parameters in each type of obesity were all within the normal range, significant differences were found in these parameters between obese women with high levels of BMI and WHR (Type-III) and the nonobese group were observed for these parameters. For women with Type-III obesity in each group, mean BMI values were 29.26, 28.95, and 28.49 and mean WHR values were $0.968,1.020$, and 1.013 , respectively.

In conclusion, the most "dangerous" subgroup of obesity appeared to be Type-III obesity, because of the apparent metabolic complications associated with excessive abdominal fat. These findings suggest the importance of obesity in precipitating the metabolic abnormalities associated with the amount of body fat and an abdominal body fat distribution.

(Received, Sep. 2. 1994)

\section{References}

1) Barakat, H. A., Burton, D. S., Carpenter, J. W., Holbert, D. and Israel, R. G. Body fat distribution, plasma lipoproteins and the risk of coronary heart disease of male subjects. Int. J. Obesity, (1988), 12, 473-480.

2) Billewicz, W. Z., Kemsley, W. F. F. and Thomson, A. M. Indices of adiposity. Br. J. Prev. Soc. Med., (1962), 16, 183-188.

3) Björntorp, P., Gustafsson, A. and Persson, B. Adipose tissue fat cell size and number in relation to metabolism in endogenous hypertriglyceridemia. Acta Med. Scand., (1971), 190, 363-367.

4) Björntorp, P. The associations between - obesity. adipose tissue distribution and disease. Acta Med. Scand. suppl., (1988), 723, 121-134.

5) Björntorp, P. 'Portal' adipose tissue as a generator of risk factors for cardiovascular disease and diabetes. Arteriosclerosis, (1990), 10, 493-496.

6) Castelli, W. P. Epidemiology of coronary heart disease: the Framingham study. Am. J. Med., (1984). 76, 4-12.

7) Després, J. P., Nadeau, A., Tremblay, A., Ferland, M., Moorjani, S., Lupien, P. J., Theriault, G., Pinault, S. and Bouchard, C. Role of deep abdominal fat in the association between regional adipose tissue distribution and glucose tolerance in obese women. Diabetes, (1989 a), 38, 304-309.

8) Després, J. P., Moorjani, S., Ferland, M., Tremblay, A., Lupien, P. J., Nadeau, A., Pinault, S., Theriault, G. and Bouchard, C. Adipose tissue distribution and plasma lipoprotein levels in obese women. Importance of intra-abdominal fat. Arteriosclerosis, (1989b), 9, 203-210.

9) Després, J. P., Moorjani, S., Lupien, P. J., Tremblay, A., Nadeau, A. and Bouchard, C. Regional distribu tion of body fat, plasma lipoproteins, and car. diovascular disease. Arteriosclerosis, (1990), 10. 497-511.

10) Friedewald, W. T., Levy, R. I. and Fredrickson, D S. Estimation of the concentration of low-density lipoprotein cholesterol in plasma, without use of the preparation ultracentrifuge. Clin. Chem., (1972), 18, 499-502.

11) Fujioka, S., Matsuzawa, Y., Tokunaga, K. and Tarui, S. Contribution of intra-abdominal fat accumulation to the impairment of glucose and lipid metabolism in human obesity. Metabolism, (1987), 36, 54-59. 
12) Goldbourt, U. and Medalie, J. H. Weight-height indices. Br. J. Prev. Soc. Med., (1974), 28, 116-126.

13) Haffner, S. M., Stern, M. P., Hazuda, H. P., Pugh, J., Patterson, J. K. and Malina, R. Upper body and centralized adiposity in Mexican Americans and non-Hispanic whites: relationship to body mass index and other behavioral and demographic variables. Int. J. Obesity, (1986), 10, 493-502.

14) Hubert, H. B., Feinleip, M., McNamara, P. M. and Castelli, W. P. Obesity as an independent risk factor for cardiovascular disease : a 26-year follow-up of participants in the Framingham heart study. Cir culation, (1983), 63, 968-977.

15) Kannel, W. D., Brand, N., Skinner, J. J., Dawber, T. K. and McNamara, P. M. The relation of adiposity to blood pressure and development of hypertension. The Framingham study. Ann. Intern. Med., (1967). 67, 48-59.

16) Kannel, W. B., Gordon, T. and Castelli, W. P. Obesity lipids, and glucose intolerance: The Framingham study. Am. J. Clin. Nutr., (1979), 32, 1238-1245.

17) Kaye, S. A., Folsom, A. R., Prineas, R. J., Potter, J. D. and Gapstur, S. M. The association of body fat distribution with lifestyle and reproductive factors in a population study of postmenopausal women. Int. J. Obesity, (1990), 14, 583-591.

18) Khoala, T. and Lowe, C. R. Indices of obesity derived from body weight and height. Br. J. Prev. Soc. Med., (1967), 21, 122-128.

19) Kissebah, A. H., Vydelingum, N., Murray, R., Evans, D. J., Hartz, A. J., Kalkhoff, R. K. and Adams, P. W. Relation of body fat distribution to metabolic complications of obesity. J. Clin. Endocrinol. Metab., (1982), 54, 254-260.

20) Kissebah, A. H., Freedman, D. S. and Peiris, A. N. Health risks of obesity. Med. Clin. North Am., (1989), 73, 111-138.

21) Komiya, S. Methods for the assessment of human body composition: skinfold thickness and bioelec. trical impedance measurements. Ann. Physiol. Anthrop., (1991), 10, 3-17 (in Japanese).

22) Lanska, D. J., Lanska, M. J., Hartz, A. J. and Rimm, A. A. Factors influencing anatomic location of fat tissue in 52953 women. Int. J. Obesity, (1985), 9. 29-38.

23) Leonhardt, W., Haller, H. and Hanefeld, M. The adipocyte volume in human adipose tissue. II. Observations in diabetes mellitus, primary hyper- lipoproteinemia and weight reduction. Int. J. Obesity, (1978), 2, 429-439.

24) Matter, S., Weltman, A. and Stamford, B. A. Body fat content and serum lipid levels. J. Am. Dietet. Ass., (1980), 77, 149-152.

25) Myers, A. R., Epstein, F. H., Dodge, H. J. and Mikkelsen, W. M. The relationship of serum uric acid to risk factors in coronary heart disease. Ann. J. Med., (1968), 45, 520-528.

26) Peiris, A. N., Hennes, M. I., Evans, D. J., Wilson, C. R., Lee, M. B. and Kissebah, A. H. Relationship of anthropometric measurements of body fat distribu. tion to metabolic profile in premenopausal women. Acta Med. Scand. suppl., (1988), 723, 179-188.

27) Peiris, A. N., Sothmann, M. S., Hennes, M. I., Lee, M. B., Wilson, C. R., Gustafson, A. B. and Kissebah, A. H. Relative contribution of obesity and body fat distribution to alterations in glucose insulin homeostasis:predictive values of selected indices in premenopausal women. Am. J. Clin. Nutr., (1989 a), 49, 758-764.

28) Peiris, A. N., Sothmann, M. S., Hoffmann, R. G., Hennes, M. I., Wilson, C. R., Gustafson, A. B. and Kissebah, A. H. Adiposity, fat distribution, and cardiovascular risk. Ann. Intern. Med., (1989 b), 110, 867-872.

29) Pouliot, M. C., Després, J. P., Nadeau, A., Tremblay, A., Moorjani, S., Lupien, P. J., Theriault, G. and Bouchard, C. Associations between regional body fat distribution, fasting plasma free fatty acid levels and glucose tolerance in premenopausal women. Int. J. Obesity, (1989), 14, 293-302.

30) Seidell, J. C., Björntorp, P., Sjöström, L., Sannerstedt, R., Krotkiewski, M. and Kvist, H. Regional distribution of muscle and fat mass in men-new in sight into the risk of abdominal obesity using com. puted tomography. Int. J. Obesity, (1989), 13. 289-303.

31) Seidell, J. C., Björntorp. P., Sjostrōm, L., Kvist, H. and Sannerstedt, R. Visceral fat accumulation in men is positively associated with insulin, glucose, and C-peptide levels, but negatively with testosterone levels. Metabolism, (1990 a), 39, 897-901.

32) Seidell, J. C., Bakker, C. J. G. and Van der Kooy, K. Imaging techniques for measuring adipose tissue distribution- a comparison between computed tomography and I. S. T. magnetic resonance. Am. J. Clin. Nutr., (1990 b), 51, 953-957. 
33) Shimokata, H., Tobin, J. D., Muller, D. C., Elahi, D., Coon, P. J. and Andres, R. Studies in the distribution of body fat: I. Effects of age, sex, and obesity. J. Gerontol., (1989), 44, M 66-M 73.

34) Simopoulos, A. P. and Van Itallie, T. B. Body weight, health and longevity. Intern. Med., (1984), 100, 285-295.

35) Staessen, J., Fagard, R. and Amery, A. The relation. ship between body weight and blood pressure. J. Hum. Hypertension. (1988), 2, 207-217.

36) Stern, M. P. and Haffner, S. M. Body fat distribution and hyperinsulinemia as risk factors for diabetes and cardiovascular disease. Arteriosclerosis, (1986) , 6, 123-130

37) Tokunaga, K., Ishikawa, K., Matsuzawa, Y., Sudo, H., Yamamoto, A. and Tarui, S. Serum lipoprotein profile in Japanese obese children. Int. J. Obesity, (1982), 6, 399-404.

38) Tonkelaar, I. D., Seidell, J. C., Van Noord, P. A. H., Baanders-Van Halewijn, E. A., Jacobus, J. H. and Bruning, P. F. Factors influencing waist/hip ratio in randomly selected pre $^{-}$and post-menopausal women in the Dom-project (preliminary results) Int. J. Obesity, (1989), 13, 817-824.

39) Tonkelaar, I. D., Seidell, J. C., Van Noord, P. A. H., Baanders-Van Halewijn, E. A. and Ouwehand, I. J. Fat distribution in relation to age, degree of obesity, smoking habits, parity and estrogen use : a cross-sectional study in 11825 Dutch women par. ticipating in the Dom-project. Int. J. Obesity, (1990). 14, 753-761.

40) Vague, J. La differenciation sexuelle - facteur determinant des formes de l'obésité. Presse Med., (1947). 30, 339-340.

41) Vague, J. The degree of masculine differentiation of obesities: a factor determining predisposition to diabetes, atherosclerosis, gout and uric calculus disease. Am. J. Clin. Nutr., (1956), 4, 20-34.

42) Womersley, J. and Durnin, J. V. G. A. A comparison of the skinfold method with extent of 'overweight' and various weight-height relationships in the assessment of obesity. Br. J. Nutr., (1977), 38. 271-284. 